\title{
Lobular Capillary Hemangioma in the Posterior Trachea: A Rare Cause of Hemoptysis
}

\author{
Ford Turner Amy and Diaz-Guzman Enrique \\ Division of Pulmonary, Critical Care and Sleep Medicine, Department of Internal Medicine, Chandler Hospital and Kentucky Clinic, \\ University of Kentucky, Lexington, KY 40536, USA \\ Correspondence should be addressed to Ford Turner Amy, afordturner@gmail.com
}

Received 24 September 2012; Accepted 22 October 2012

Academic Editors: L. Borderías and M. Plataki

Copyright ( 2012 F. T. Amy and D.-G. Enrique. This is an open access article distributed under the Creative Commons Attribution License, which permits unrestricted use, distribution, and reproduction in any medium, provided the original work is properly cited.

Lobular capillary hemangiomas ( $\mathrm{LCH})$ have been cited in the literature as a rare potential cause for recurrent hemoptysis. They are mostly associated with cutaneous and mucosal surfaces. Rarely do they affect the trachea and associated airways in adults. Lobular capillary hemangiomas can be associated with previous trauma to the airway; however, drugs, hormonal shifts, viral oncogenes, production of angiogenic factors, and cytogenetic clonal deletion abnormalities can also influence these lesions. We document a case of a posterior wall tracheal hemangioma with associated recurrent hemoptysis in a 22-year-old male on testosterone therapy. An LCH attached to the posterior tracheal wall can be technically difficult to remove due to risk of perforation and bleeding. There have been no cases documented of posterior wall $\mathrm{LCH}$.

\section{Introduction}

Lobular capillary hemangiomas ( $\mathrm{LCH})$, formally known as pyogenic granuloma, usually present as a painless, bleeding mass adherent to the mucosal or cutaneous surfaces of the upper airways. Most commonly they are present on the lip, nose, oral cavity, and tongue. According to a pathologic review of 639 vascular lesions of the upper airway [1], they are more common in males less than 18 years and females of reproductive age. Most cases reviewed involve pediatric patients. They have only recently been documented in the trachea [2-6]. No cases have been reported of a posterior wall LCH. We report on a 22-year-old male that presented with recurrent hemoptysis. Upon bronchoscopic evaluation, he had an adherent vascular lesion pathologically found to be a LCH attached to his posterior tracheal wall.

\section{Case Presentation}

A 22-year-old male presented to our clinic with recurrent episodes of hemoptysis over a 4-week period with 3 distinct events. He stated that this started with an incidence of heavy coughing. He then would cough up to $2-4$ tablespoons of blood. After presentation to the emergency room, it was initially thought this was related to epistaxis, and he was sent home with treatment for allergic rhinitis. He had no other symptoms, denying fever, weight loss or gain, chest pain, easy bruising, dyspnea, or rash. He did complain of chronic postnasal drip, nasal congestion, and occasional pruritis, which he attributed to allergies. He had a past medical history of eosinophilic colitis, obsessive-compulsive disorder, history of an aneurismal bone cyst status postremoval, and allergic rhinitis. He had also been recently diagnosed with hypogonadism over the last 5 months, and was on injectable testosterone supplementation. He denied smoking, alcohol, and illicit drug use and had no known inhalant exposures and trauma to the airway that he could recall. His family history included a brother with eosinophilic colitis and his mother had vascular ectasias of her spinal cord. He did note that these episodes seemed to occur 5 days after his dose of intramuscular testosterone. Physical exam was otherwise unremarkable and laboratory values were unrevealing. Computed tomography did not reveal any notable lesion of the upper airway or lung parenchyma. 


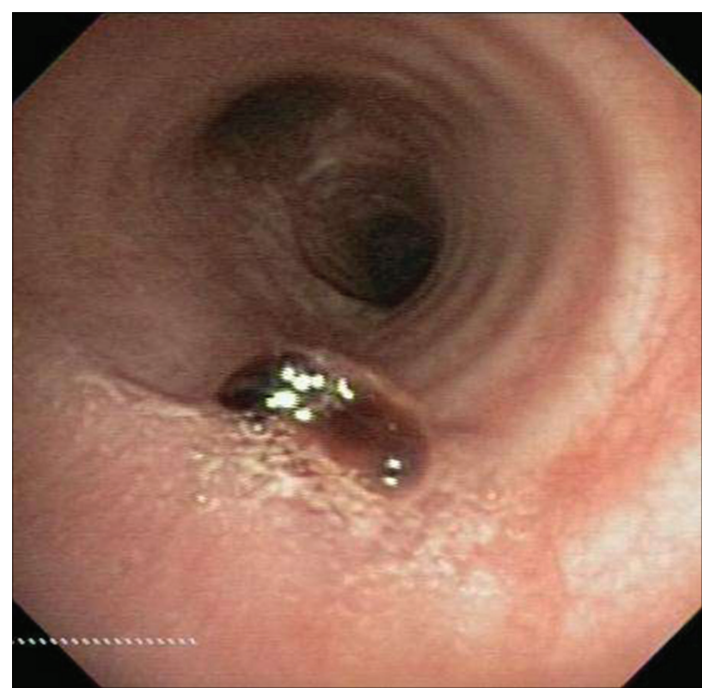

FIGURE 1

Upon flexible bronchoscopic evaluation, the following lesion was seen in the distal trachea (Figure 1). The purple, vascular lesion was approximately $1-1.5 \mathrm{~cm}$ in size located $3 \mathrm{~cm}$ from the carina at the 5 o'clock position along the posterior wall attached by a short pedicle. A biopsy was taken at that time which only showed fibrin products and inflammatory cells. Hemostasis was difficult to obtain without use of cold saline, several injections of topical epinephrine and Argon Plasma Coagulation. Due to unavailability of pathology and the location of the lesion, the patient was taken to the operating suite where a therapeutic flexible bronchoscope was used with utilized. The lesion was obtained by electrocautery loop snare and endoscopic basket. The pathology revealed the diagnosis of lobular capillary hemangioma (Figures 2 and 3). The superficial portions of the lesion had undergone secondary, nonspecific changes including stromal edema, capillary dilation, inflammation, and a granulation tissue reaction. It demonstrated diagnostic, lobular arrangements of capillaries at its base, which consisted of discrete clusters of endothelial cells. The cellular architecture was made up of an inflammatory infiltrate of neutrophils and monocytes.

Upon followup, the patient had no hemoptysis episodes and has subsequently stopped his testosterone therapy.

\section{Discussion}

Lobular capillary hemangioma is a well-known entity that commonly involves skin and oral/nasal mucosa, developing rapidly over a number of days to weeks. Its cause is not well defined but certain postulates correlate to previous trauma, hormonal shifts, viral oncogenes, Bartonella infection, production of angiogenic factors, and cytogenetic clonal deletion abnormalities, although certain studies have disproven some of the above $[7,8]$. Other causal relationships suggest certain drugs can also cause these lesions, such as retinoid therapy [9] and others. Our patient had recently been started on testosterone therapy, which could be coincidental or have

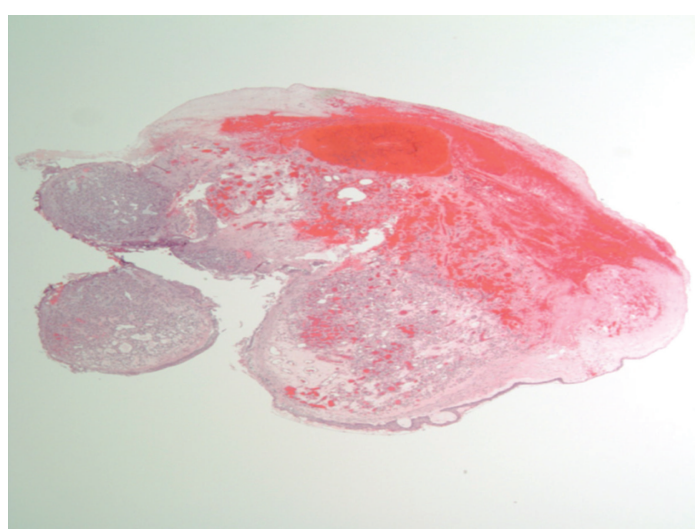

Figure 2

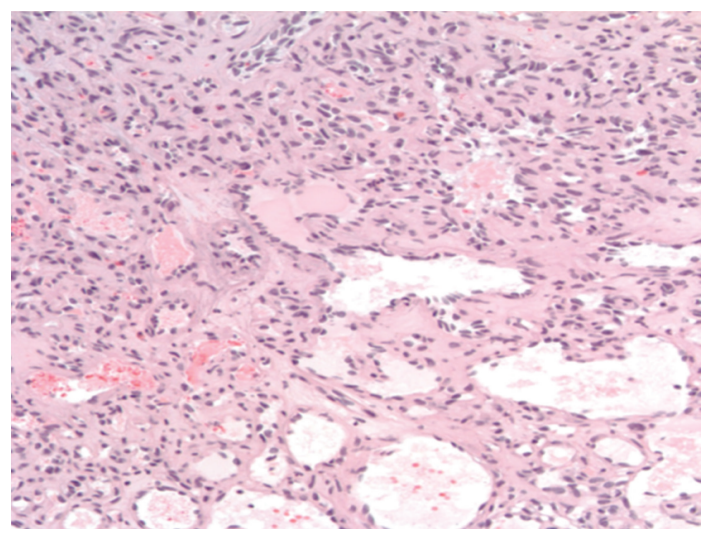

FIGURE 3

influenced the necessary hormonal shifts to promote such a vascular lesion in a susceptible host. These lesions have commonly and extensively been studied in late pregnancy, arising mostly in the airway mucosa from the influence of female hormones on vascular development [10]. Though the relationship between testosterone and angiogenesis has been correlated in bench studies $[11,12]$, there has yet to be specific research regarding its role in this particular type of tumor in this instance. Also of note is that our patient had a previous history of a vascular lesion in his tibia that had been removed at the age of 16 , requiring surgery and an oral endotracheal intubation. His mother had vascular lesions in her spine found incidentally on imaging, suggesting a genetic proclivity in his family.

Regardless of the causal relationships, the position of the lesion became technically difficult due to the posterior wall location and the vascular structure of the tumor itself. The treatment in general for these lesions depends on the extent or size of the lesion, age, comorbidities, and other factors contributing to the overall clinical scenario. Because of inherent thinness of the posterior tracheal wall, there is a risk of iatrogenic tears and perforation. These defects are treated with various approaches; surgical intervention is sometimes required [13]. Lobular capillary hemangiomas have been successfully treated with various other methods involving cryotherapy, YAG laser therapy [14], topical 
or intralesional steroids or neoplastic agents, propranolol (in children), and surgical excision [15]. If bleeding is a potential risk, such as it is with vascular tumors, having interventional bronchoscopy (e.g., rigid bronchoscopy) available during the removal would be highly suggested. The lesion in this case was easily removed with flexible bronchoscopy, and hemostasis was controlled due to the small pedicle size. Our patient did not experience any complications and is currently symptom free.

\section{Conclusion}

Lobular capillary hemangioma found in the trachea continues to be a rare entity and has yet to be described abutting the posterior wall. Posterior laryngeal wall lesions can be challenging due to risk of laceration and perforation and the appropriate equipment needs to be readily available to avoid complications. Though no direct causal link could be found in this patient, we believe that hormonal supplementation may have played a role in its development.

\section{Consent}

The patient gave written consent to have the case reported.

\section{References}

[1] S. E. Mills, P. H. Cooper, and R. E. Fechner, "Lobular capillary hemangioma: the underlying lesion of pyogenic granuloma. A study of 73 cases from the oral and nasal mucous membranes," The American Journal of Surgical Pathology, vol. 4, no. 5, pp. 470-479, 1980.

[2] S. Irani, T. Brack, M. Pfaltz, and E. W. Russi, "Tracheal lobular capillary hemangioma: a rare cause of recurrent hemoptysis," Chest, vol. 123, no. 6, pp. 2148-2149, 2003.

[3] M. Chawla, C. Stone, and M. J. Simoff, "Lobular capillary hemangioma of the trachea: the second case," Journal of Bronchology and Interventional Pulmonology, vol. 17, no. 3, pp. 238-240, 2010.

[4] K. Madhumita, K. P. Sreekumar, H. Malini, and R. Indudharan, "Tracheal haemangioma: case report," Journal of Laryngology and Otology, vol. 118, no. 8, pp. 655-658, 2004.

[5] I. Porfyridis, C. Zisis, K. Glinos et al., "Recurrent cough and hemoptysis associated with tracheal capillary hemangioma in an adolescent boy: a case report," Journal of Thoracic and Cardiovascular Surgery, vol. 134, no. 5, pp. 1366-1367, 2007.

[6] A. R. Zambudio, M. J. Calvo, J. T. Lanzas, J. G. Medina, and P. P. Paricio, "Massive hemoptysis caused by tracheal hemangioma treated with interventional radiology," Annals of Thoracic Surgery, vol. 75, no. 4, pp. 1302-1304, 2003.

[7] S. J. Patrice, K. Wiss, and J. B. Mulliken, "Pyogenic granuloma (lobular capillary hemangioma): a clinicopathologic study of 178 cases," Pediatric Dermatology, vol. 8, no. 4, pp. 267-276, 1991.

[8] I. Levy, J. M. Rolain, H. Lepidi et al., "Is pyogenic granuloma associated with Bartonella infection?" Journal of the American Academy of Dermatology, vol. 53, no. 6, pp. 1065-1066, 2005.

[9] J. P. Campbell, R. C. Grekin, C. N. Ellis, S. S. MatsudaJohn, N. A. Swanson, and J. J. Voorhees, "Retinoid therapy is associated with excess granulation tissue responses," Journal of the American Academy of Dermatology, vol. 9, no. 5, pp. 708$713,1983$.

[10] H. Jafarzadeh, M. Sanatkhani, and N. Mohtasham, "Oral pyogenic granuloma: a review," Journal of oral science, vol. 48, no. 4, pp. 167-175, 2006.

[11] D. P. Sieveking, P. Lim, R. W. Y. Chow et al., "A sex-specific role for androgens in angiogenesis," Journal of Experimental Medicine, vol. 207, no. 2, pp. 345-352, 2010.

[12] I. Franck-Lissbrant, S. Häggström, J. E. Damber, and A. Bergh, "Testosterone stimulates angiogenesis and vascular regrowth in the ventral prostate in castrated adult rats," Endocrinology, vol. 139, no. 2, pp. 451-456, 1998.

[13] T. Schneider, K. Storz, H. Dienemann, and H. Hoffmann, "Management of iatrogenic tracheobronchial injuries: a retrospective analysis of 29 cases," Annals of Thoracic Surgery, vol. 83, no. 6, pp. 1960-1964, 2007.

[14] M. S. Bédard and J. Boulanger, "Treatment of lobular capillary hemangioma with the Nd:YAG laser: retrospective case series of 25 patients," Journal of Cutaneous Medicine and Surgery, vol. 13, no. 3, pp. 181-182, 2009.

[15] H. C. Hölbe, P. J. Frosch, and R. A. Herbst, "Surgical pearl: ligation of the base of pyogenic granuloma-an atraumatic, simple, and cost-effective procedure," Journal of the American Academy of Dermatology, vol. 49, no. 3, pp. 509-510, 2003. 


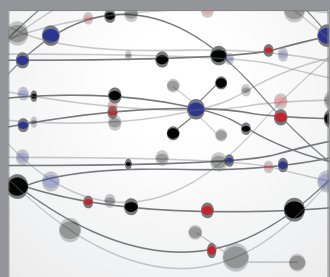

The Scientific World Journal
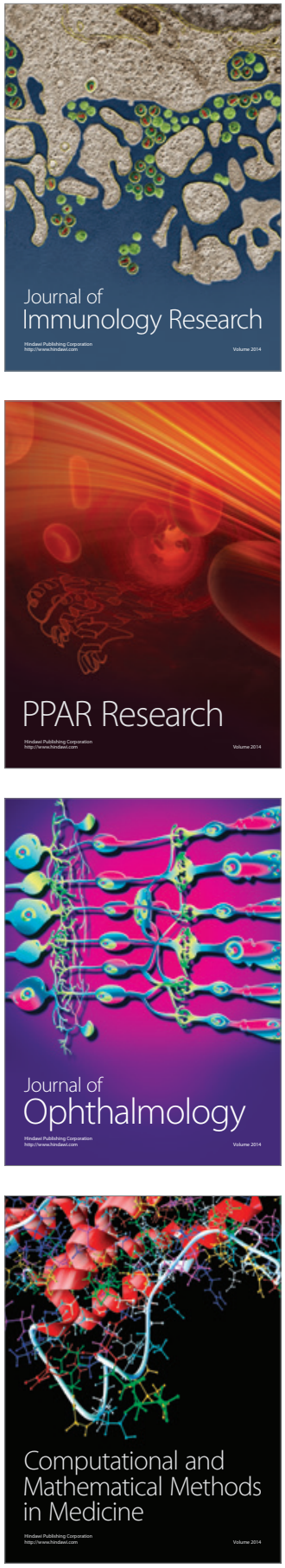

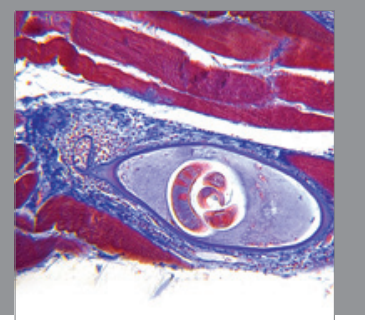

Gastroenterology

Research and Practice
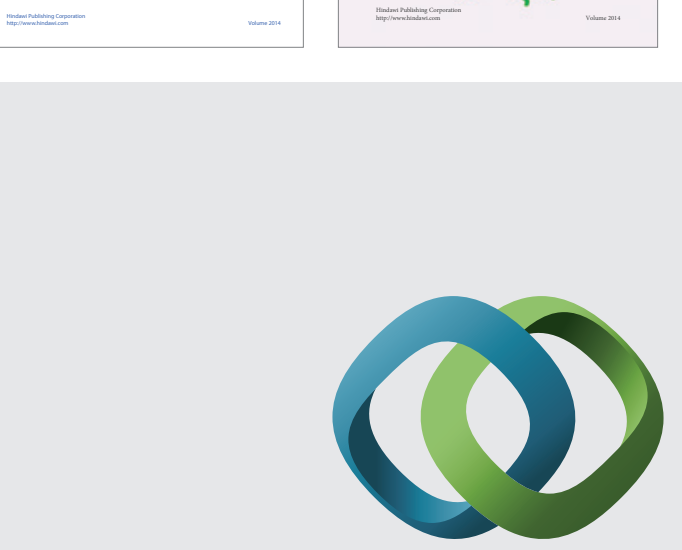

\section{Hindawi}

Submit your manuscripts at

http://www.hindawi.com
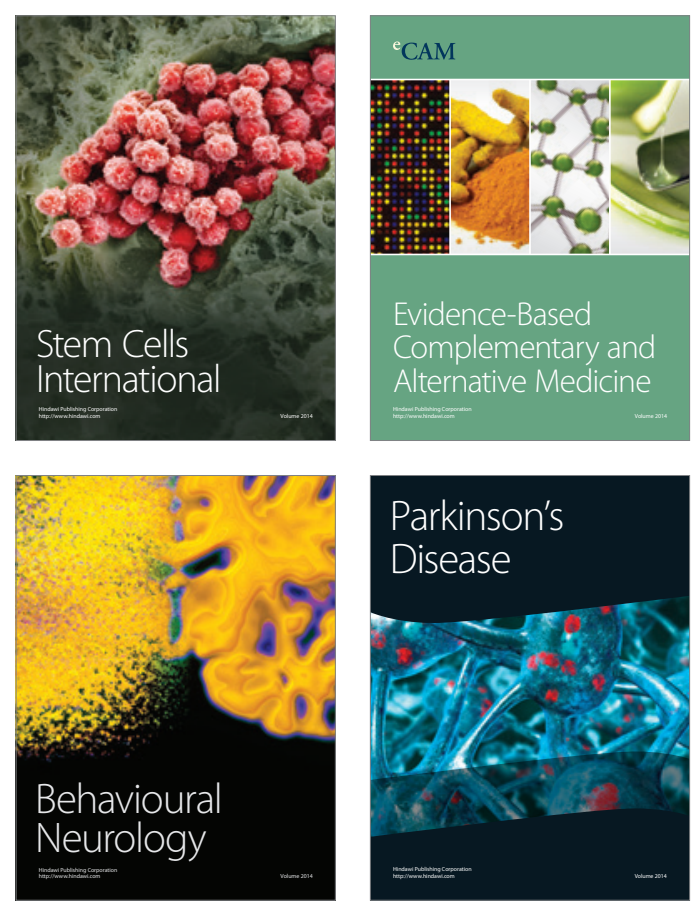

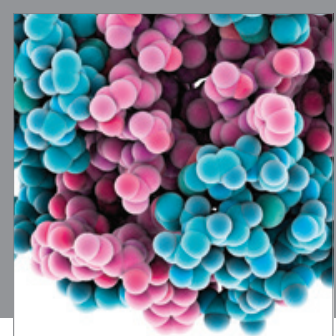

Journal of
Diabetes Research

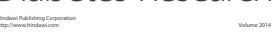

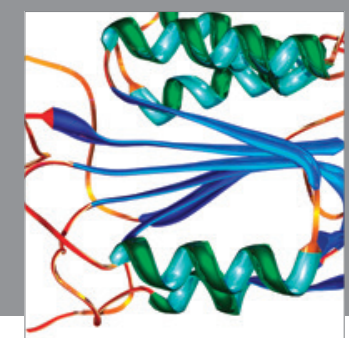

Disease Markers
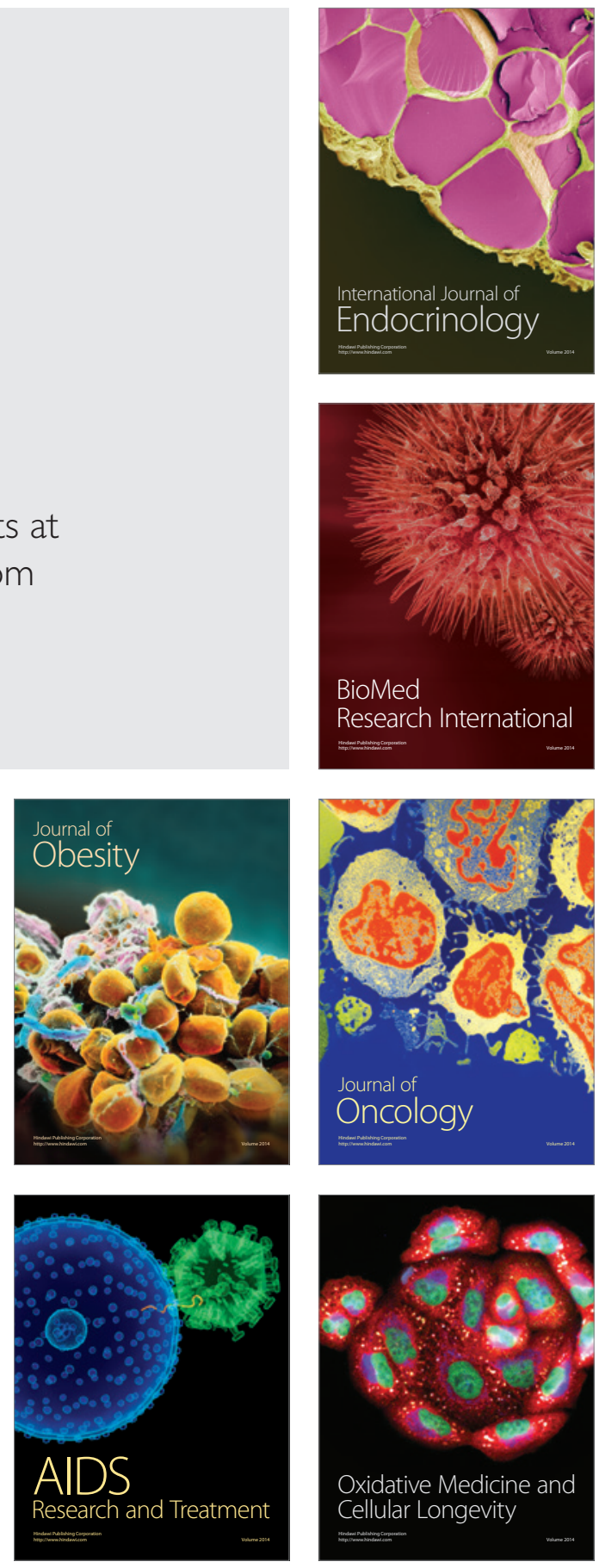